\title{
Analysis of Synergistic Effect Based on Regional Fintech and Regional Inclusive Finance
}

\author{
Lin Luo ${ }^{1, \#}$, Chuanhao Wei ${ }^{2, \#}$, Ruijie Xu ${ }^{3, \#, *}$ \\ ${ }^{1}$ College of Economics Shenzhen University, Shenzhen University, 518000, Shenzhen, China \\ ${ }^{2}$ Shenzhen University Webank Institute of Fintech, Shenzhen University, 518000, Shenzhen, China \\ ${ }^{3}$ Shenzhen University Webank Institute of Fintech, Shenzhen University, 518000, Shenzhen, China \\ *Corresponding author:(xuruijie1012@163.com) \\ \# equally contributed to this works
}

\begin{abstract}
Fintech not only brings impact to the traditional inclusive finance, but also provides a new direction for its development. There is a synergistic effect between them. This paper selects several fintech and inclusive financial indicators to reflect the order parameter and uses AHM (Attribute Hierarchy Model) and EWM (Entropy Method) to weight the order parameter. The synergy degree evaluation model of fintech and traditional inclusive finance is constructed using the order parameter method of system synergy degree measurement. The results show that the coordination degree between fintech and inclusive finance shows an overall decreasing trend of type ' $\mathrm{L}$ ', and the coordination of the composite system of the two is negatively correlated with the difference in the order degree of the subsystems within the selected period. Therefore, suggestions can be proposed that when formulating the development plans of the two, regions need to fully consider the synergy between the two. In addition to ensuring that the policy for one side has a positive effect on the other side, it is necessary to synchronize the development of the two as much as possible and enhance the coordination of the composite system.
\end{abstract}

Keywords: Synergy system model, Fintech, Traditional inclusive finance, AHM-EWM

\section{INTRODUCTION}

Fintech and inclusive finance not only have a significant impact on the world financial service system, but also play an important role in balancing income distribution and improving the market structure. At present, it is not difficult to see the synergy between financial technology and inclusive finance, whether it is blockchain finance on which digital currencies are advancing around the world or big data finance on which Internet companies collect customer information. Exploring the synergistic effect between the two can further develop the breadth of their development, promote their cross-integration, and truly realize the use of science and technology empower inclusive finance. Given this study, the synergistic effect between fintech and inclusive finance is helpful to provide more targeted measures for the common development of both and can be applied to more scenarios of inclusive finance with fintech as a tool.

At present, the research on the relationship between fintech and inclusive finance is rising. Meng Nana and Su Qin ${ }^{[1]}$ combined with 'Catfish effect' and 'Crowdingout effect' and used iterative GMM method to explore the influence of fintech and inclusive finance; Xue Ying and $\mathrm{Hu} \mathrm{Jian}^{[2]}$ explored how to promote the high-quality development of the current economy from the perspective of digital inclusive finance combined with the current fintech; Hubin and Cheng Xuejun ${ }^{[3]}$ further explained the development strategy of China's digital inclusive finance facing global financial competition from the two dimensions of finance and technology combined with the development indicators of inclusive finance in various countries; Li Mingxian and $\mathrm{He} \mathrm{You}^{[4]}$ tried to use fintech as a tool to achieve the goal of inclusive finance by its availability, affordability and sustainability; Lu Minfeng ${ }^{[5]}$ and others take the contradiction of inclusive finance as a logical starting point to analyze how to use fintech to alleviate the antagonism of its fundamental contradiction, and finally make the policy and commercial nature of inclusive finance organically unified in the opposition; Zhang $\mathrm{Xun}^{[6]}$ found that digital economy and inclusive finance 
jointly promoted China's inclusive growth based on the empirical analysis of sub-samples.

However, it is not difficult to see that the current part of the research on fintech and inclusive finance only stays based on quantitative analysis, and the degree of synergies between fintech and inclusive finance has not yet been quantified by specific indicators. In this paper, the AHM-EWM method is used to quantitatively analyze the synergistic effect between fintech and inclusive finance. Firstly, the current situation of the two is analyzed to determine their synergistic relationship. Then, the order parameters of the two are selected and quantified, and the synergetic model is constructed. Finally, the results are analyzed by empirical cases. This paper deeply analyzes the synergy between fintech and inclusive finance, and puts forward suggestions for developing a financial service system based on the analysis results, to promote the synergy between the two and build a more perfect regional financial system.

\section{RESEARCH ON THE RELATIONSHIP AND MODEL OF SYNERGY BETWEEN FINTECH AND INCLUSIVE FINANCE}

\subsection{Study on the Synergy between Fintech and Inclusive Finance}

The International Financial Stability Board defines fintech as technology-driven financial services innovation, generating new business models, applications, business processes, or products to promote financial services development. In recent years, the development of fintech has been irresistible. Artificial intelligence, big data, blockchain, and other technologies have subverted the traditional financial industry, making the scene of the financial industry more diversified, expanding the breadth and depth of financial services to the real economy. It has an outstanding contribution to national financial security and financial development. And from top to bottom, in various industries, fintech also emits its charm, which provides a dual guarantee of theory and practice for the Internet of Vehicles, gene diagnosis and treatment, wearable devices, and other fields. It can be seen that fintech has entered a steady stream of power to develop services and infrastructure in various fields.

Inclusive finance has been practiced and succeeded in some South American countries as early as the twentieth century compared to fintech. It is defined as providing financial services to all groups at affordable costs based on equality of opportunity and commercial sustainability and hopes to solve the problems of the large income gap and slow economic development in some regions. Nowadays, the development of inclusive finance has also achieved fruitful results, which has played a positive role in serving small and micro enterprises and poverty alleviation. Based on the synergistic effect, this paper explores the interaction between fintech and traditional inclusive finance from the perspective of inclusive finance and analyzes how to use fintech to promote the development of inclusive finance while using inclusive finance to feedback fintech to provide direction.

\subsection{Research on the Synergy Theory and Model between Fintech and Inclusive Finance}

The synergy theory proposed by physicist Hermann Haken mainly explores how an open system far from equilibrium can exchange with the outside world, and how to transform the structure of time, space, and function from disorder to order through their synergy after reaching a certain critical value. Specifically, it is based on system theory, information theory, cybernetics, mutation theory, aiming at different fields to establish a set of mathematical models and processing schemes, from micro transition to macro process describes the system from disorder to order. There is a synergistic relationship between fintech and inclusive finance. Therefore, this paper regards the relationship between fintech and inclusive finance as a composite model, studies the synergy degree of the composite system, constructs the evaluation model of synergy degree between fintech and inclusive finance, and reveals the evolution law and trend of the system. The synergy between the two is shown in Fig. 1.

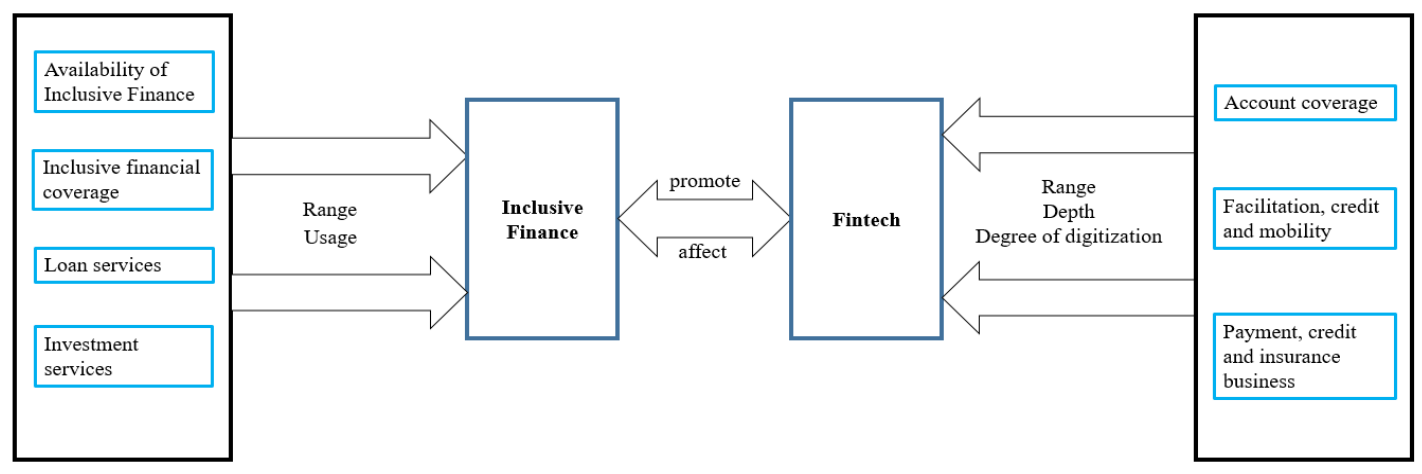

Fig. 1 Synergy between Fintech and Inclusive Finance 


\section{SELECTION AND WEIGHTING OF ORDER PARAMETERS}

\subsection{Selection of Order Parameters}

Based on synergetic theory, fintech and inclusive finance are regarded as a composite system composed of two subsystems with different attributes and structures. Order parameter refers to the parameter variable that determines the macro behavior of the system and represents the degree of ordering of the system, which determines the final structure and degree of ordering of the system.

Fintech is the explanatory variable of this paper, using the DFIIC (Digital Inclusive Financial Index) of the Digital Finance Research Center of Peking University as an indicator to reflect the level of fintech. The first-level indicators include three dimensions: the first is coverage breadth, including the second-level indicator account coverage, reflecting the level of fintech coverage. Two is the depth of use, including secondary indicators payment services, credit services, insurance services, reflecting the use of fintech services. Three is the degree of digitization, including mobile, credit, convenience, reflecting the combination of fintech.
Traditional inclusive finance is the explained variable in this paper. Considering the availability and accuracy of data, most of the indicators of traditional inclusive finance are selected from the research projects in the China Statistical Yearbook and Almanac of China's Finance and Banking. The first level indicators include two dimensions: one is the breadth of financial services. The task of inclusive finance is to provide appropriate financial services to all sectors of society, so the coverage of financial services is the basic condition. This indicator also includes four secondary indicators, namely, statistics of financial institutions, insurance density, per capita consumption expenditure of rural residents, and the number of settlement accounts per unit of the bank, to measure the breadth of financial services from the aspects of coverage and availability. The second is the level of financial services. Whether the society can provide highquality financial services to all sectors of society, especially the middle and lower classes, is an intuitive manifestation of the level of inclusive finance. This indicator also includes three secondary indicators: fixed asset investment of financial institutions, real income capital of small loan companies, and fixed asset investment of the whole society. These financial services can be used as representatives to reflect the public's enjoyment of financial services. Both order parameters are selected as shown in Tab. 1.

Table 1 Fintech and Inclusive Financial Order Parameters

\begin{tabular}{|c|c|c|c|c|}
\hline $\begin{array}{c}\text { Order } \\
\text { parameter }\end{array}$ & First-grade indexes & Second-grade indexes & Positive indicators & Unit \\
\hline \multirow{7}{*}{$\begin{array}{l}\text { Fintech } \\
\text { System }\end{array}$} & Coverage breadth & Account coverage rate & + & Percentage $\%$ \\
\hline & \multirow{3}{*}{ Depth of use } & Payment business & + & M RMB \\
\hline & & Credit business & + & M RMB \\
\hline & & Insurance business & + & M RMB \\
\hline & \multirow{3}{*}{ Level of digitization } & Mobility & + & Percentage $\%$ \\
\hline & & Creditization & + & Percentage $\%$ \\
\hline & & Facilitation & + & Percentage $\%$ \\
\hline \multirow{7}{*}{$\begin{array}{l}\text { Inclusive } \\
\text { financial } \\
\text { system }\end{array}$} & \multirow{4}{*}{$\begin{array}{l}\text { Financial services } \\
\text { breadth }\end{array}$} & Statistics of financial institutions & + & M RMB \\
\hline & & Insurance density & + & M RMB /Hectare \\
\hline & & $\begin{array}{c}\text { Per capita consumption expenditure of rural } \\
\text { residents }\end{array}$ & + & M RMB \\
\hline & & Number of RMB Bank Settlement Accounts & + & M RMB \\
\hline & \multirow{3}{*}{ Use of financial services } & $\begin{array}{c}\text { Agricultural Loans in Local and Foreign Currency of } \\
\text { Financial Institutions }\end{array}$ & + & M RMB \\
\hline & & \begin{tabular}{|c|c|} 
The real capital of small loan companies \\
\end{tabular} & + & M RMB \\
\hline & & Investment in fixed assets of the whole society & + & M RMB \\
\hline
\end{tabular}

\subsection{Weighting of the Order Parameter}

\subsubsection{Logarithmic Efficacy Function Method}

To maintain the stability of the index, the logarithmic function method is used. The formula is as follows:

$$
d=\frac{\log x-\log x^{l}}{\log x^{h}-\log x^{l}} \times 100 \%
$$

For the positive index, the $95 \%$ quantile of the actual value of the index data in 2011 is taken as the upper limit $x^{h}$, and the $5 \%$ quantile is the lower limit $x^{l}$. For reverse indicators. Take 95 percent of the actual value of the fixed 2011 indicator data as the upper limit $x^{h}$ and 5 percent as the lower limit $x^{l}$.

\subsubsection{AHM EWM Model}

\subsubsection{Construction of AHM}

In 1977, Saaty proposed AHP (Analytic Hierarchy Process) to calculate the order of elements through a 
matrix feature vector. In 1998, a new unstructured decision-making method - AHM (Attribute Hierarchical Model) was proposed, which greatly simplified its calculation. The method of AHM is to establish a multilevel structure. Combined with professional literature and subjective judgment, a scale is given for each layer of attribute index, that is, the influence proportion, to construct the comparison matrix of each layer, according to the following formula into attribute judgment matrix:

$$
u_{i j}=\left\{\begin{array}{l}
\frac{k}{k+1}, b_{i j}=k, i \neq j \\
\frac{k}{k+1}, b_{i j}=\frac{1}{k}, i \neq j \\
0, i=j
\end{array}\right.
$$

Then the attribute weights of all indicators are obtained by the following formula as weights:

$$
W_{c}(i)=\frac{2}{n(n-1)} \sum_{j=1}^{n} u_{i j}
$$

\subsubsection{Construction of EWM}

EWM (Entropy Method) is a mathematical method to determine the discrete degree of an index. The larger the discrete degree, the greater the impact of the index on the comprehensive evaluation, so the greater the weight in the index. Assuming that there are $\mathrm{m}$ samples and $\mathrm{n}$ evaluation indexes, the original data matrix is formed to eliminate the zero value in the data, and the dimensionless processing is carried out. The processed data is denoted as $\mathrm{i}, \mathrm{j}$.

STEP1: Calculate the proportion of sample $i$ under indicator $\mathrm{j}$ :

$$
P_{i j}=\frac{z_{i j}}{\sum_{i=1}^{m} z_{i j}}
$$

STEP2: Calculation of entropy for the jth index:

$$
e_{j}=-k \sum_{i=1}^{m} p_{i j} \ln p_{i j}
$$

STEP3: Calculation of variance coefficient for indicator $\mathrm{j}$ (information utility value):

$$
d_{j}=1-e_{j}
$$

STEP4: Get the weight of each index:

$$
\omega_{j}=\frac{d_{j}}{\sum_{i=1}^{n} d_{j}}
$$

\subsubsection{Calculation of Coupling Weight Coefficient}

Confirming weights can be divided into subjective assignment methods and objective assignment methods. This paper uses AHM (Attribute Hierarchy Model) in the subjective assignment method and EWM (Entropy Method) in the objective assignment method to determine weights by coupling coefficient.

After calculating the subjective weight $W_{s u b}$ and objective weight $W_{o b}$, the coupling coefficient method can effectively reflect the relative weight relationship of each index and its weight proportion on the whole. Therefore, this method is used to obtain the total weight.

$$
W=\frac{W_{s u b} W_{o b}}{\sum_{j=1}^{n} W_{s u b} W_{o b}}
$$

\section{CONSTRUCTION OF SYNERGETIC MODEL}

\subsection{Construction of Subsystems}

The traditional inclusive finance and fintech are regarded as a composite system $S=\left\{S_{1}, S_{2}\right\}$, where $S_{1}$ is the traditional inclusive finance subsystem and $S_{2}$ is the fintech subsystem. Considering the subsystem $S_{j}(j \in[1,2])$, we assume that the order parameter is $e_{j}=\left(e_{j 1}, e_{j 2}, e_{j 3}, \ldots, e_{j n}\right), \quad n \geq 1, b_{j i} \leq e_{j i} \leq a_{j i}$, $i \in[1, n]$, were $\alpha_{\mathrm{ji}}$, and $\beta_{\mathrm{ji}}$ are the upper and lower bounds of the order parameter $e_{j i}$ at the critical point of system stability. Then the system order degree of component $e_{j i}$ of the order parameter of a subsystem $S_{j}$ is:

$$
u_{j}\left(e_{j i}\right)=\left\{\begin{array}{l}
\frac{e_{j i}-b_{j i}}{a_{j i}-b_{j i}}, i \in[1, l] \\
\frac{a_{j i}-e_{j i}}{a_{j i}-b_{j i}}, i \in[l+1, n]
\end{array}\right.
$$

Using the linear weighting method to integrate, $\omega_{j}$ is the weight of the jth index. The formula is as follows:

$$
u_{j}\left(e_{j}\right)=\sum_{k=1}^{n} \omega_{j} u_{j}\left(e_{j i}\right)
$$

\subsection{Synergy Model}


The synergy degree of traditional inclusive finance and fintech composite system reflects the comprehensive coordination degree between the two subsystems. This paper uses the deviation coefficient $\mathrm{C}$ to measure the synergy between the two systems. The smaller the deviation coefficient $\mathrm{C}$ is, the better the synergy is, and vice versa.

$$
C=2 \sqrt{1-\frac{u_{1}\left(e_{1}\right) u_{2}\left(e_{2}\right)}{\left[\frac{u_{1}\left(e_{1}\right)+u_{2}\left(e_{2}\right)}{2}\right]^{2}}}
$$

\section{SYNERGY EFFECT AND INFLUENCE ANALYSIS BASED ON FINTECH AND INCLUSIVE FINANCE}

\subsection{Research Objects and Data Presentation}

Table 2 Order Parameter Index Data of National Fintech System and Inclusive Financial System

\begin{tabular}{|c|c|c|c|c|c|c|c|c|c|}
\hline Subsystem & Index & 2011 & 2012 & 2013 & 2014 & 2015 & 2016 & 2017 & 2018 \\
\hline \multirow{6}{*}{$\begin{array}{l}\text { Fintech } \\
\text { System }\end{array}$} & Account coverage rate $/ 10^{3}$ & 1.063 & 2.493 & 3.740 & 5.267 & 5.924 & 6.462 & 7.620 & 8.740 \\
\hline & Depth of use $/ 10^{3}$ & 1.455 & 3.612 & 5.354 & 4.776 & 5.384 & 6.674 & 9.105 & 8.912 \\
\hline & Payment business $/ 10^{3}$ & 1.443 & 2.156 & 3.002 & 4.538 & 5.810 & 7.211 & 7.620 & 8.087 \\
\hline & Insurance business $/ 10^{3}$ & 1.461 & 5.401 & 14.171 & 15.671 & 11.991 & 15.747 & 19.384 & 19.968 \\
\hline & Credit business $/ 10^{3}$ & 1.454 & 3.028 & 2.650 & 2.593 & 4.122 & 4.602 & 5.456 & 5.530 \\
\hline & Level of digitization $/ 10^{3}$ & 1.436 & 4.114 & 7.392 & 8.027 & 12.389 & 10.245 & 9.889 & 11.895 \\
\hline \multirow{7}{*}{$\begin{array}{l}\text { Inclusive } \\
\text { Financial } \\
\text { System }\end{array}$} & Statistics of financial institutions $/ 10^{3}$ & 5.008 & 5.261 & 5.821 & 6.969 & 7.705 & 9.061 & 10.528 & 11.013 \\
\hline & Insurance density $/ 10^{3}$ & 1.047 & 1.131 & 1.266 & 1.558 & 1.766 & 2.258 & 2.632 & 2.724 \\
\hline & $\begin{array}{l}\text { Per capita consumption expenditure of } \\
\text { rural residents } / 10^{3}\end{array}$ & 5.221 & 5.908 & 7.485 & 8.383 & 9.223 & 10.130 & 10.955 & 12.324 \\
\hline & $\begin{array}{c}\text { Number of RMB Bank Settlement } \\
\text { Accounts } / 10^{3}\end{array}$ & 2.824 & 3.170 & 3.558 & 3.977 & 4.439 & 4.939 & 5.483 & 6.119 \\
\hline & $\begin{array}{l}\text { Agricultural Loans in Local and Foreign } \\
\text { Currency of Financial Institutions } / 10^{5}\end{array}$ & 1.460 & 1.763 & 2.089 & 2.360 & 2.635 & 2.823 & 3.095 & 3.268 \\
\hline & $\begin{array}{l}\text { The real capital of small loan companies } \\
\qquad / 10^{3}\end{array}$ & 3.319 & 5.147 & 7.133 & 8.283 & 8.459 & 8.234 & 8.270 & 8.363 \\
\hline & $\begin{array}{l}\text { Investment in fixed assets of the whole } \\
\text { society } / 10^{5}\end{array}$ & 3.115 & 3.747 & 4.463 & 5.120 & 5.620 & 6.065 & 6.412 & 6.457 \\
\hline
\end{tabular}

\subsection{Index Weight Calculation of Order Parameter}

Based on standardizing the order parameter index data of the fintech system and the inclusive financial system, Formulas (2) (3) are used to calculate the weight of each index AHM index, and Formulas (4) (7) are used to calculate the weight of each index EWM index. Finally, Formula (8) is used to calculate the coupling weight to obtain the weight result. The weight relationship of each index is shown in Figure 2.

The degree of digitization ( 0.458$)$, coverage $(0.148)$, and payment level $(0.144)$ in the fintech level account for a larger proportion, while inclusive finance accounts for a larger proportion of agricultural loans (0.317) and bank accounts $(0.226)$. This stems from the fact that fintech has provided great convenience for traditional financial
This paper takes the two subsystems of inclusive finance and fintech as the research objects. From the perspective of system analysis, it selects the order parameters representing inclusive finance that reflect the breadth, depth, and degree of digitalization, and the order parameters representing fintech that reflect the breadth and use of financial services, and evaluates the coordinated development level of inclusive finance and fintech.

Inclusive financial system order parameter index comes from Almanac of China's Finance and Banking (2011 2018) and China Statistical Yearbook. The order parameter index data of the fintech system are derived from Peking University Digital Inclusive Finance Index (2011 2020). The specific indicators and index data are shown in Table 2. 


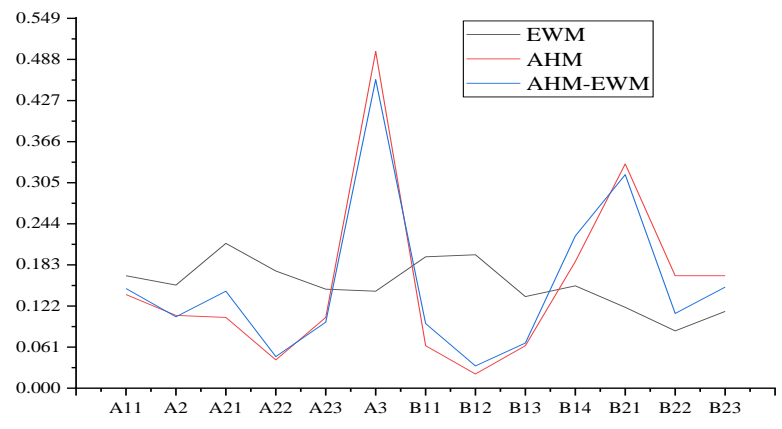

Figure 2 Weights of Specific Indicators of Each Order Parameter

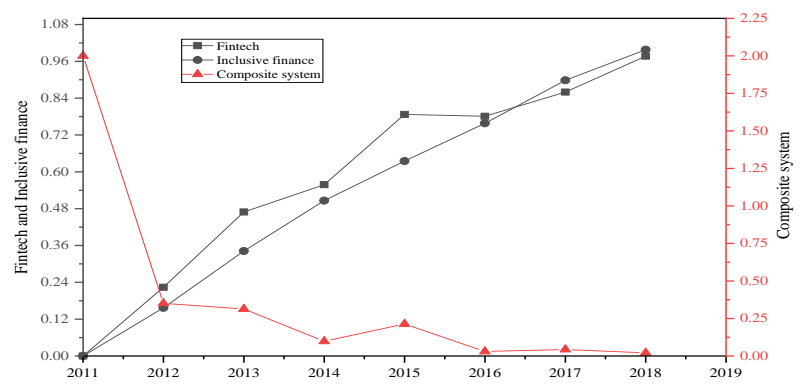

Figure 3 Changes in the Order of the Inclusive Financial System, Fintech System, and the Deviation Coefficient of the Composite System

Order degree analysis of subsystem. It can be seen from Figure 3 that the order degrees of the inclusive financial system and the fintech system show a stable upward trend in the selected period. The order of the inclusive financial system ranged from the base point in 2011 to 0.998 in 2018, and the order of the fintech system ranged from the base point in 2011 to 0.977 in 2018 . It shows that the contribution of the two subsystems to the composite system is increasing. Comparing the two subsystems, it can be seen that there is an intersection in the order curve of the two subsystems. In $2011 \sim 2016$, the order of the fintech system was higher than that of traditional inclusive finance. After 2016, the order of inclusive financial system has surpassed that of the fintech system.

Synergy analysis of a composite system. Figure 3 shows that the deviation coefficient curve shows a good trend from high deviation coefficient to low deviation coefficient from the perspective of the overall trend, indicating that the coordination degree of the composite system is getting better and better. From the perspective of absolute value, the deviation coefficient curve shows a small wave trend. Despite this, it maintains at a low numerical deviation coefficient level, indicating that the coordination of the two subsystems is better. The overall change of coordination degree of a composite system can be divided into the following three stages:

Phase I: $2011 \sim 2014$. The deviation coefficient curve shows a downward trend year by year, and the order degree curve of the two subsystems rises steadily, indicating that inclusive finance and fintech continue to develop stably and have good coordination.

Phase II: $2014 \sim 2016$. The deviation coefficient curve increases and decreases alternately, and the order curve of the two subsystems first diverge and then converges. It shows that the development of the inclusive financial system is seriously lagging behind fintech from 2014 to 2015 . The increase of development differences between subsystems leads to the aggravation of incoordination between systems, which leads to the decline of coordination of composite systems.

Phase III: $2016 \sim 2018$. The deviation coefficient curve shows a small wave trend, and the order degree curve of the subsystem rises steadily. In this period, the order difference first increases and then decreases, while the coordination shows a slight decrease and then increases. It shows that the coordination of composite systems is related to the difference of order degree between subsystems: the difference of order degree increases and the coordination decreases; the degree of coordination is reduced, and the coordination is enhanced

Based on the analysis and data of the above three stages, it can be concluded that the coordination of the composite system is negatively correlated with the absolute value difference between the order degrees of the two subsystems. Starting from the basic point in 2011, when the difference between the order degree values of the two subsystems is reduced, the coordination of the composite system becomes better. When the numerical difference of order degree between the two subsystems increases, the coordination of the composite system becomes worse. Therefore, the following suggestions are put forward for the conclusions:

i. Participants in inclusive finance and fintech development should ensure stable growth rates of indicators and maintain sustainable and stable development of inclusive finance and fintech.

ii. Due to the development of inclusive finance and fintech difference, too big will lead to poor coordination of the composite system, so in the development process, the two should remain relatively synchronous, pay attention to coordinated development.

iii. In pursuing fintech or inclusive finance policies, countries need to consider the impact of policy implementers on non-implementers and, to the extent possible, select policies that make them more collaborative.

\section{CONCLUSION}

Based on the principle of order parameter construction and the perspective of system analysis, this paper selects the representative order parameter index data of the inclusive financial system and the fintech system from 2011 to 2018. AHM and EWM are used to determine the weight of each index to calculate the order 
degree, and then the synergy evaluation model is constructed. The deviation coefficient reflects the coordination degree to measure the coordination of inclusive finance and the fintech composite system. The conclusions are as follows:

i. In the selected period order degree of the fintech system and inclusive financial system is steadily increasing. It shows that the two subsystems show a stable development trend, and the contribution to the composite system is rising, with an increase of $336.16 \%$ and $535.67 \%$, respectively.

ii. In the selected period, the coordination of the composite system is related to the order difference between the fintech subsystem and the inclusive financial subsystem. When the difference between the ordering values of the two subsystems is reduced, the coordination of the composite system is optimized. When the numerical difference of order degree between the two subsystems increases, the coordination of the composite system becomes worse.

iii. The validity and rationality of the model in the study area are verified.

\section{REFERENCES}

[1] Meng Nana \& Su Qin. (2020). Crowd-out effect or catfish effect: A study on the impact of financial technology on traditional inclusive finance. Modern Finance (Journal of Tianjin University of Finance and Economics) (01), 56-70. DOI: 10.19559 /j.cnki.12-1387.2020.01.005.

[2] Xue Ying \& Hu Jian. (2020). Financial technology boosts high-quality economic development: theoretical logic, practical basis, and path selection. Reform (03), 53-62. DOI:

[3] $\mathrm{Hu}$ Bin \& Cheng Xuejun. (2020). Financial technology, digital financial inclusion, and national financial competitiveness. Journal of Wuhan University (Philosophy and Social Sciences Edition) (03), 130-141. doi:10.14086/j.cnki. wujss. 2020.03.013

[4] Li Mingxian \& He You. (2019). The tool value and realization dilemma of financial technology under the goal of rural inclusive finance. Journal of South China Normal University (Social Science Edition) (01), 59-65+190. DOI:CNKI: SUN: HNSB.0.201901-012.

[5] Lu Minfeng, Ma Jingwei \& Wang Zugang. (2019). Research on the basic contradiction map and solution path of inclusive finance under the background of financial technology. Financial Theory and Practice (08), 1-7. DOI:

[6] Zhang Xun, Wan Guanghua, Zhang Jiajia \& He
Zongyue. (2019). Digital Economy, Inclusive Finance and Inclusive Growth. Economic Research (08), 71-86. DOI:

[7] Li Helong, Xu Jie \& Wang Cunhua. (2021). The coupling relationship between technological innovation and financial innovation in the Guangdong-Hong Kong-Macao Greater Bay Area. Science and Technology Management Research (14), 56-64. DOI:CNKI:SUN: KJGL.0.2021- 14008 . 